\title{
Single incision laparoscopic surgery - is it time for laboratory skills training?
}

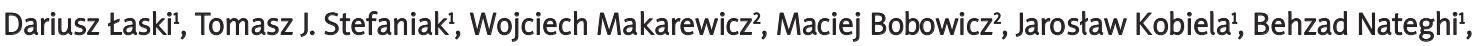 \\ Monika Proczko', Ilona Madejewska ${ }^{1}$, Zbigniew Gruca ${ }^{3}$, Zbigniew Śledzinski ${ }^{1}$ \\ 1Department of General, Endocrine and Transplant Surgery, Medical University of Gdansk, Poland \\ 2Department of Oncological Surgery, Medical University of Gdansk, Poland \\ 3 Pomeranian Foundation for Progress in Surgery, Poland
}

Videosurgery Miniinv 2013; 8 (3): 216-220

DOI: 10.5114/wiitm.2011.33811

\begin{abstract}
Introduction: With the introduction of new surgical equipment, there is always the need for new, more advanced training. The authors try to answer whether the use of the newest generation tools has an impact on achieving better results in single incision laparoscopic surgery (SILS) technique during the exercises in the surgical skills laboratory. Material and methods: There were 51 participants in the study: 44 'novices' and 7 'experts'. All subjects performed the 'advanced grasping' exercise according to the FLS programme manual using four types of laparoscopic approach including two SILS ports and SILS-dedicated instruments. The outcome measures involved task completion time and the number of errors.

Results: Tasks using straight laparoscopic instruments set together with classic three-port access as well as SILS access ports were finished significantly faster when compared with SILS-dedicated instruments $(p<0.05)$. There were no significant differences in performance times between the two setups with straight instruments $(p<0.05)$ and both setups with SILS-dedicated instruments, irrespective of the use of curved or dynamic articulated tools. Students with no previous laparoscopic experience had significantly worse task completion times in all tasks in comparison to students with laparoscopic laboratory training and the 'experts' group.

Conclusions: The use of the straight instruments in the SILS technique remain similar to its performance in full triangulation. SILS-dedicated instruments paradoxically increase the task completion time irrespective of possessed skills. The study showed the necessity of a SILS-dedicated tools training programme.
\end{abstract}

Key words: surgical education, surgery didactics, single incision laparoscopic surgery, minimally invasive surgery, articulated tools, curved tools.

\section{Introduction}

New, increasingly refined operative techniques are being developed at a high speed and are introduced into clinical practice even before the latest applications become widely accepted, just to mention single incision laparoscopic surgery (SILS), natural orifice transluminal endoscopic surgery (NOTES) and operative robots. Advanced laboratory and clinical surgical training should be developed to follow this progress in a timely manner providing training based on dozens of technical modifications and an enormous amount of constantly improved tools. 


\section{Aim}

The main aim of this paper is to assess the differences between new operative techniques such as SILS in comparison to 'classic' laparoscopic techniques used to date. The influence of current laparoscopic training on outcomes of simple exercises using SILSdedicated instruments was assessed. Finally and most importantly the study is designed to answer whether the introduction of the next generations of increasingly sophisticated tools has an impact on achieving better results in SILS technique during the training outside the operating theatre in the skills laboratory.

\section{Material and methods}

The study group consisted of 51 participants divided into two main arms. The first arm - the 'novices' group - consisted of 44 students of the Faculty of Medicine, Medical University of Gdansk, Poland, with interest in surgery, and the second arm, named the 'experts' group, consisted of 7 surgical residents and qualified surgeons. The 'novices' group was subdivided into two populations depending on the laparoscopic experience. Twenty-three were students without any previous laparoscopic experience, whereas 21 were students who had some experience gained during the Basic Laparoscopic Skills laboratory workshops. The workshops were voluntary and optional and were incorporated in the students' facultative surgical curriculum [1, 2]. It was structured laparoscopic training organized by the General, Endocrine and Transplant Surgery Department of the Medical University of Gdansk, Poland and conducted in the Education Centre of the Pomeranian Foundation for Progress in Surgery. It consisted of $21 \mathrm{~h}$ of simple laparoscopic tasks performed on box trainers and a virtual reality laparoscopic trainer. The course followed the principles of the Fundamentals of Laparoscopic Surgery Programme [3].

In the 'experts' arm of the study there were three general surgical residents with more than 50 laparoscopic operations performed before the commencement of the study, as well as four qualified general surgeons with interest in laparoscopic surgery (over 150 laparoscopic procedures each) but without extensive previous SILS experience (less than 5 procedures).

All participants were asked to perform a simple laparoscopic task checking the navigation ability and control of the classic and SILS-dedicated laparoscopic instruments. The objective of the task was to place ten different shaped buttons in a cup. The exercise was similar to the 'advanced grasping' task according to the Fundamentals of Laparoscopic Surgery Programme manual [3]. The outcome measures included task completion time and number of errors such as letting the elevated button fall, hitting the cup or hitting any of the walls of the box trainer. Each of the above errors was given 10 penalty seconds added to the total time. Every participant performed the task using four settings of ports and instruments, repeating the task twice for each of the settings. The settings were as follows:

1. classic three-port access and straight laparoscopic instruments - grasper and dissector (Karl Storz, Tuttlingen, Germany),

2. SILS access port and straight laparoscopic instruments - grasper and dissector,

3. SILS access port and dynamic articulated tools 'SILS Hand Instruments' (Covidien, Massachusetts, USA) - referred to later in the text as "dynamic articulated SILS tools",

4. SILS access port and curved Dapri system instruments (Karl Storz, Tuttlingen, Germany) - referred to later in the text as "curved SILS tools".

The tasks were performed simultaneously on two box trainers equipped with a $30^{\circ}$ laparoscopic camera (Karl Storz, Tuttlingen, Germany). One set contained an X-Cone access port (Karl Storz, Tuttlingen, Germany) whereas the other was equipped with a Cuschieri Endocone access port (Karl Storz, Tuttlingen, Germany).

The study was designed to eliminate the firstpass effect by randomization of the instruments as well as the type of access port used. Randomization was done by draw before every performed task for a particular participant.

\section{Statistical analysis}

Analysis was performed for both study arms as well as subgroups in both 'novices' and 'experts' groups. Statistical computer software Statistica 11.0 PL (StatSoft, Poland) licensed for the Medical University of Gdansk, Poland was used. ANOVA analysis of variation and post-hoc tests were used and $p<0.05$ was established as statistically significant.

\section{Results}

All the groups of participants - (i) experts, (ii) students without any laparoscopic experience and (iii) students who undertook Basic Laparoscopic Skills 


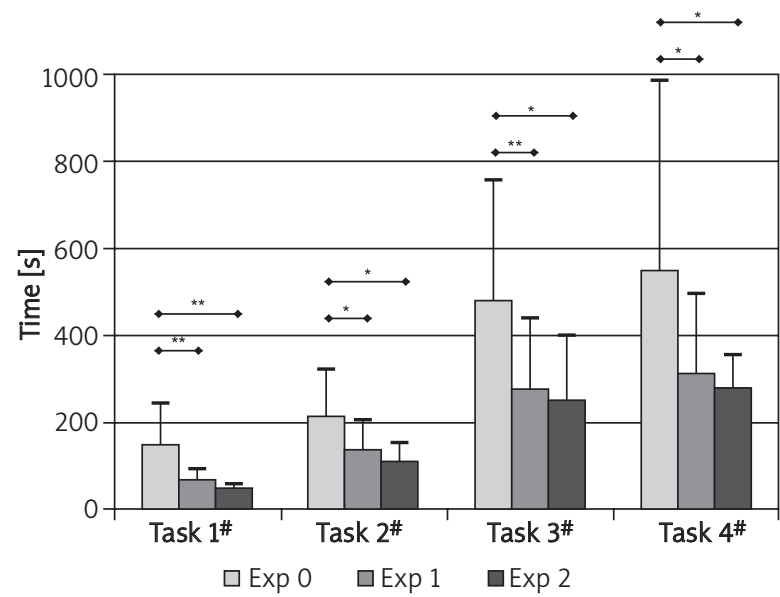

ANOVA ${ }^{*} p<0.05 ;$ Scheffe post-hoc ${ }^{*} p<0.05,{ }^{* *} p<0.001$

Figure 1. Mean time to complete tasks (1 - classic triangulation, 2 - straight tools through SILS port, 3 - SILS dynamic articulated tools, 4 - SILS curved tools) dependent on experience (0 - student without any training, 1 - students after our basic surgical curriculum, 2 - laparoscopy experts). Intragroup variance: Exp 0 - overall ANOVA $p<0.05$; Scheffe post-hoc: Task 1 vs. Task $2 p=$ NS; Task 3 vs. Task $4 p=$ NS; Task 1 vs. Task 3 and Task $4 p<0.05$; Task 2 vs. Task 3 and Task $4 p<0.05$; Exp 1 and Exp 2 - the same pattern of statistical relations

training - had considerable difficulties performing tasks using SILS-dedicated instruments. Tasks using straight laparoscopic instruments set together with classic three-port access as well as SILS access ports were finished significantly faster when compared with SILS-dedicated instruments $(p<0.05)$. Nonetheless, there were no statistically significant differences in performance times between the two setups with straight instruments $(p<0.05)$. Comparable results were also obtained for both setups with SILS-dedicated instruments, irrespective of the use of curved or dynamic articulated tools (Figure 1).

Each task was performed twice. There were no statistically significant differences between the two repetitions for either of the study arms. Independently of the participant's experience there was no statistically significant learning effect during the repetition.

Students with no previous laparoscopic experience had significantly worse task completion times in all tasks in comparison to students with laparoscopic laboratory training and the experts group. The results of the students with basic laparoscopic laboratory training but no clinical experience did not differ from the results of the 'experts' group (Figure 1).

\section{Discussion}

The presented study shows that single incision laparoscopic surgery using SILS-dedicated instruments is difficult irrespectively of previous laparoscopic experience. It also shows that without specific training, the SILS-dedicated instruments do not improve the results of a simple laparoscopic task even in the hands of an experienced laparoscopic surgeon. Antoniou et al., based on a review of the literature on SILS, concluded that handling SILS-dedicated instruments causes many technical difficulties $[4,5]$. Crossing of these instruments is often necessary, which necessitates changing of previously learned "laparoscopic" behaviours. It requires complete ambidexterity and adaptation to the new type of instruments' navigation [6-17]. Non-intuitive preparation in the narrow space with altered visualization of the operative field and the need for strict cooperation with the assistant holding the laparoscopic camera forces a new learning curve for both the surgeon and the entire surgical team [6-17]. The findings of our study lead to similar conclusions.

The task completion times were shorter for the classic straight laparoscopic instruments via a SILS port in comparison to the SILS-dedicated instruments $(p<0.05)$, for all the study groups.

The dynamic articulated tools provide good triangulation at the maximum flexure. Moreover, they allow rotation of the instrument's tip along the axis. However, crossing of the instruments necessitates smooth conversion from classic navigation to navigation with inversion of the axial movement at the crossing axis. Tools with 'fixed' curves provide triangulation without the need to cross instruments. Nevertheless, lack of the instrument's tip rotation in the longitudinal axis forces different navigation and, for the inexperienced user, precise elevation of objects becomes particularly difficult. Therefore it seems obvious that operating with the use of SILS-dedicated instruments requires separate skills and additional training irrespective of previous laparoscopic experience. Similar conclusions were published by Santos et al. [18].

Interestingly, there was no difference in the results of the task when using classic laparoscopic instruments during the operation via three separate 
ports and a SILS port. Possibly, it might be associated with the fact that navigation with classic straight tools is simpler and more intuitive despite the lack of triangulation and narrowing of the visual field. This pattern was observed in both groups of experts and novices. On the other hand, the task presented in the study might not have been difficult enough. Had a more difficult task been chosen, such as laparoscopic knot tying (although rarely performed in SILS operations) where the movement is more complex and requires better triangulation, a difference between the SILS approach for straight instruments and SILS-dedicated instruments might have appeared and favoured specialized tools.

Antoniou et al. in their study noted that the use of classic versus SILS-dedicated instruments during the SILS cholecystectomy does not influence morbidity, success rate or operative time [15]. In the present study, the significantly shorter task completion time for both groups, 'experts' as well as 'novices', might suggest that the straight instruments may also be used in low-complexity SILS operations such as cholecystectomy. There are numerous reports on the benefits of SILS technique in various surgical procedures such as cholecystectomy [4, 5, 12, 13, 16, 17], adrenalectomy $[8,9,11]$ and bariatric surgery [14]. Still, there is lack of comparative data on the efficacy of straight and SILS-dedicated instruments in complex procedures. Nonetheless, based on the Ahmed et al. analysis, one can notice that some authors use straight instruments via SILS ports even in procedures requiring extensive preparation (e.g. nephrectomy or extraction of the kidney for transplantation) and more complex instruments [6].

The lack of significant differences between consecutive repetitions indicates that single incision laparoscopic surgery is a demanding procedure requiring quite long training. 'Experts' probably would achieve a satisfactory level of proficiency earlier than 'novices', but the study clearly indicates that such specialized training is needed even for experienced laparoscopists. Training in the laparoscopic surgical skills laboratory, physical trainers, animal models or cadavers is recommended before live human operations $[18,19]$. Followers of such an approach, Santos et al. (in surgery) and Kaouk et al. (in urology), advocate introduction of SILS techniques into the residents' training curriculum $[18,19]$.

The efficacy of laparoscopic training in the surgical skills laboratory and transfer of the acquired skills into the operating theatre has been proven in multiple studies [20-25]. Nonetheless, many authors emphasize the lack of evidence for the necessity of SILS laboratory training [18]. On the other hand, SILS is considered by some authors a method with unproved efficacy and superiority over classic laparoscopy $[6,15]$. The procedure has increased complexity and costs to achieve a slightly better cosmetic effect, and its efficacy has not yet been proved in large scale prospective randomized controlled trials. Slightly shortened hospitalization time and lack of cost-effectiveness studies are being challenged in the literature reviews $[6,15]$. And, finally, there still remains one unanswered question: whether such sophisticated SILS training should be mandatory for all surgical residents, or voluntary and implemented only in high-volume SILS surgery centres.

\section{Conclusions}

The use of straight instruments in the SILS technique allows the 'advanced grasping' task completion times to remain similar to its performance in full triangulation regardless of the previous laparoscopic experience. SILS-dedicated instruments paradoxically increase the task completion time irrespective of possessed skills. The results support observation of problems in the use of SILS-dedicated tools even in laparoscopically experienced hands.

The study showed the necessity for a SILS-dedicated training programme regardless of the surgical advancement before the first live operation.

\section{Acknowledgments}

The authors would like to thank the Pomeranian Foundation for Surgery Development for cooperation and support. We would also like to gratefully acknowledge the cooperation and technical support of $\mathrm{Mr}$ Dawid Kalociński from Medim company (representative of Karl Storz) and Mr Tomasz Wasiak from Covidien company for providing the above-specified instruments and access ports that allowed us to conduct the present study.

\section{References}

1. Gruca Z, Kobiela J, Stefaniak T. Surgical simulators in didactics of minimally invasive techniques. Videosurgery Miniinv 2008; 3 : 30-4.

2. Łaski D, Stefaniak TJ, Makarewicz W, et al. New surgical curriculum of pre-graduation surgical education. First approach in Poland. Videosurgery Miniinv - in press. 
3. Fundamentals of laparoscopic surgery. Available at: http://www. flsprogram.org

4. Antoniou SA, Pointner R, Granderath FA. Single-incision laparoscopic cholecystectomy: a systematic review. Surg Endosc 2011 25: 367-77.

5. Shussman N, Schlager A, Elazary R, et al. Single-incision laparoscopic cholecystectomy: lessons learned for success. Surg Endosc 2011; 25: 404-7.

6. Ahmed K, Wang TT, Patel VM, et al. The role of single-incision laparoscopic surgery in abdominal and pelvic surgery: a systematic review. Surg Endosc 2010; 25: 378-96.

7. Desai MM, Aron M, Canes D, et al. Single-port transvesical simple prostatectomy: initial clinical report. Urology 2008; 72: 960-5.

8. Budzyński A, Pędziwiatr M, Matłok M, et al. Preliminary experience with transperitoneal single incision laparoscopic surgery adrenalectomy. Videosurgery Miniinv 2010; 5: 87-92.

9. Łosin M, Czauderna P, Gołębiewski A, Stefanowicz J. Single incision laparoscopic adrenalectomy - initial experience. Videosurgery Miniinv 2010; 5: 104-6.

10. Rispoli G, Armellino MF, Esposito C. One trocar appendectomy. Surg Endosc 2002; 16: 833-5.

11. Cywiński J, Kuzdak K, Kołomecki K. One-incision approach (SILS) for retroperitoneal videoscopic adrenalectomy. Videosurgery Miniinv 2010; 5: 70-1.

12. Hong TH, You YK, Lee KH. Transumbilical single-port laparoscopic cholecystectomy: scarless cholecystectomy. Surg Endosc 2009; 23: 1393-7.

13. Zhu JF, Hu H, Ma YZ, Xu MZ. Totally transumbilical endoscopic cholecystectomy without visible abdominal scar using improved instruments. Surg Endosc 2008; 23: 1781-4.

14. Bobowicz M, Michalik M, Orłowski M, Frask A. Bariatric single incision laparoscopic surgery - review of initial experience. Videosurgery Miniinv 2011; 6: 48-52.

15. Antoniou SA, Pointner R, Granderath FA. Single-incision laparoscopic cholecystectomy: a systematic review Surg Endosc 2011 25: 367-77.

16. Wróblewski TM, Piotrowicz S, Kotulski M, et al. No-visible-scar cholecystectomy. Videosurgery Miniinv 2010; 5: 158-60.

17. Łosin M, Czauderna P, Gołębiewski A. Single incision laparoscopic surgery cholecystectomy in children - preliminary experience. Videosurgery Miniinv 2010; 5: 139-41.

18. Santos BF, Enter D, Soper NJ, Hungness ES. Single-incision laparoscopic surgery $\left(\mathrm{SILS}{ }^{\mathrm{TM}}\right)$ versus standard laparoscopic surgery: a comparison of performance using a surgical simulator. Surg Endosc 2011; 25: 483-90.

19. Kaouk JH, Haber GP, Goel RK, et al. Single-port laparoscopic surgery in urology: initial experience. Urology 2008; 71: 3-6.

20. Ahlberg G, Enochsson L, Gallagher AG, et al. Proficiency-based virtual reality training significantly reduces the error rate for residents during their first 10 laparoscopic cholecystectomies. Am J Surg 2007; 193: 797-804.

21. Hyltander A, Liljegren E, Rhodin PH, Lönroth H. The transfer of basic skills learned in a laparoscopic simulator to the operating room. Surg Endosc 2002; 9: 1324-8.

22. Kundhal PS, Grantcharov TP. Psychomotor performance meas ured in a virtual environment correlates with technical skills in the operating room. Surg Endosc 2009; 3: 645-9.
23. Larsen CR, Soerensen JL, Grantcharov TP, et al. Effect of virtual reality training on laparoscopic surgery: randomised controlled trial. Surg Endosc 2011; 25: 166-71.

24. Schijven MP, Jakimowicz JJ, Broeders IA, Tseng LN. The Eindhoven laparoscopic cholecystectomy training course improving operating room performance using virtual reality training: results from the first E.A.E.S. accredited virtual reality trainings curriculum. Surg Endosc 2005; 9: 1220-6.

25. Seymour NE, Gallagher AG, Roman SA, et al. Virtual reality training improves operating room performance: results of a randomized, double-blinded study. Ann Surg 2002; 4: 458-63.

Received: 6.07.2012, accepted: 19.02.2013. 